\title{
The reversal of gender inequality in education, union formation and fertility in Europe
}

\author{
Jan Van Bavel*
}

\begin{abstract}
While men have always received more education than women in the past, this gender imbalance in education has recently turned around. For the first time in European history, there are now more highly educated women than men reaching the reproductive ages and looking for a partner. I expect that this will have profound consequences for the demography of reproduction because mating patterns have always implied that men are the majority in higher education. These traditional practices are no longer compatible with the new gender distribution in education. The objective of this paper is to formulate hypotheses about the consequences for reproductive behaviour in Europe. I expect the following causal chain between the reversal of the gender imbalance in education (RGIE) and fertility: RGIE creates a new, education-specific mating squeeze that affects the process and expected pattern of assortative mating, which in turns affects the timing, probability and stability of union formation, which eventually is expected to have implications for fertility. Each of the links in this chain are discussed in detail.
\end{abstract}

\section{Introduction}

In many poor countries, women are educationally strongly disadvantaged, and this is clearly connected with sustained high fertility in many of these countries. Demographers therefore argue that expanding female participation in education would greatly contribute to fertility decline and, hence, to a slowdown of population growth (Cohen 2008). In the rich countries of the West, the situation is very different. There, a major social development of the second half of the 20th century has been the spectacular increase of participation in higher education in general, and participation by women in particular. In North America and Europe

\footnotetext{
* Jan Van Bavel, Centre for Sociological Research/Family and Population Studies, Faculty of Social Sciences, University of Leuven, 3000 Leuven, Belgium. Email: Jan.VanBavel@soc.kuleuven.be
} 
today, women excel men in terms of participation and success in higher education. However, research on the demographic consequences of the reversal of gender inequality in higher education is rare, even if education, and especially women's level of education, has proven to be relevant for all kinds of demographic behaviour (Lutz et al. 1998, 2008; Vincent-Lancrin 2008).

The aim of this paper is to stimulate future empirical research about the issue in European countries. To this end, it reviews the literature to derive specific hypotheses about the potential implications of the reversal of gender inequality in higher education (abbreviated as RGIE from now on) for union formation and fertility in Europe. The underlying general hypothesis is that RGIE will have profound consequences for long-standing patterns of reproduction.

We already know that the expansion of higher education, especially among women, has led to a major postponement of the age at entry into parenthood. This effect is direct and approximately unidirectional, with few countervailing mechanisms. In contrast, I expect that RGIE will generate new indirect effects via its implications for partnership formation and dissolution. The potential indirect effects are not unidirectional. It is not just a further compositional shift towards even more highly educated women entering the dating and mating market. Rather, I argue that the turnaround of the gender imbalance from a male toward a female majority in higher education will have non-monotonic implications, with countervailing mechanisms and uncertain outcomes.

The next section briefly sketches the contours of RGIE in Europe. Then, I argue in Section 3 that we need to update the concept of the "marriage squeeze" in order to address the implications. Section 4 discusses the potential implications for the pattern of educational assortative mating. Following Oppenheimer (1988), I argue in Section 5 that the degree of difficulty that people encounter in assortative mating will have implications for the timing and probability of union formation, as well as for the stability of unions. Further down the road, the timing, probability and stability of unions will affect fertility. Section 6 speculates about these fertility implications. The conclusion gives an overview of all hypotheses formulated along the way.

\section{The rise of female participation in higher education}

In Europe, as elsewhere, university education remained an almost exclusive male privilege until deep into the 20th century (Howarth 1994; European Commission 2009). Around 1950, participation in higher education was still very low for both sexes but male enrolment ratios were more than twice as high for men as for women. From the 1960s onwards, participation in tertiary education rapidly expanded, from about 2 per cent of university-age people in 1960 to around 13 per cent in 1980 and over 25 per cent in 2000 worldwide. Initially, this rapid expansion disproportionately involved men, leading to an even widening gender 
gap in higher education to the advantage of men. However, from the 1970s onwards, the gender gap began to shrink. Since the late 1990s, more women than men have been enrolled in tertiary education (Schofer and Meyer 2005).

Generally speaking, the proportions of women in higher education were already high before the fall of the iron curtain in the former communist countries. In the Nordic countries as well, gender parity has been reached relatively early. In the German-speaking countries as well as in the Netherlands, the proportions female are relatively low. Southern and western European countries are in between. For comparison: in the US, gender parity in higher education was already reached in 1980, at a time when only three communist countries had reached that level in Europe (Bulgaria, Poland and Hungary). Canada had crossed the 50\% line by 1990 (Vincent-Lancrin 2008, 267). By 2009, all but one European country (Switzerland) had a female majority in higher education according to UNESCO statistics. Women have not only surpassed men in their participation in tertiary education, they have also surpassed them in terms of completion rates: women are more often successfully finishing their higher education and obtaining academic degrees than men. The trends in completion are even stronger than the trends for participation, implying an even wider gender gap in favour of women for completion than for participation (Buchmann and DiPrete 2006; DiPrete and Buchmann 2006; McDaniel 2010).

The fact that women more often obtain degrees in tertiary education than men does not imply that they are the majority in all fields of study. On the contrary, women and men tend to study quite different types of disciplines, leading to persistent gender segregation in some study fields. Female underrepresentation tends to be high in engineering, mathematics and computer science, and to a lesser degree in the natural sciences. In contrast, women tend to be overrepresented in education, humanities, social sciences, law and health fields (Vincent-Lancrin 2008). This pattern of choice of study discipline is consistent with what can be expected based on traditional gender roles (Bradley 2000; Charles and Bradley 2002) and has important implications for the earning potential in the paid labour market (Brown and Corcoran 1997; Jurajda 2003; Machin and Puhani 2003). Even if women generally outperform men in terms of participation and success in higher education, they continue to be underrepresented in the more lucrative and powerful positions in the labour market (Mandel and Semyonov 2006). This has implications for family formation which are in addition to the effect of the level of education (Van Bavel 2010).

\section{The education-specific mating squeeze}

In 20th-century Europe, the dominant pattern of assortative mating has been a combination of educational homogamy combined with female hypergamy and male hypogamy: women have tended to marry men who are at least as highly 
educated as themselves; conversely, men have tended to marry women who are at most as highly educated as themselves (Kalmijn 1998; Schwartz and Mare 2005; Blossfeld 2009; Esteve et al. 2011). This traditionally observed pattern reflects a combination of male and female preferences on the one hand and what is possible - given the educational distribution - on the other. Until recently, the traditional pattern was compatible with the gender-specific distribution of education levels: more highly educated men than highly educated women were available in the population. But that has turned around now. I argue that this leads to a new kind of "mating squeeze".

\subsection{Updating the concept of the marriage squeeze}

A long-standing theory in family demography holds that marriage rates for both men and women are affected by the number of suitable marriage partners available on the local marriage market. In its most basic form, the "marriage squeeze" hypothesis holds that marriage prospects are lower if the number of unmarried persons of the desired age is low. In the Western world, unmarried women are argued to suffer a marriage squeeze if the number of unmarried men who are around two years older is lower than their own number, because the age gap between husband and wife is usually around two years in the West (Schoen 1983; Crowder and Tolnay 2000).

A first useful step to investigate the implications of the reversed gender imbalance in higher education is to determine the dimensions of the marriage squeeze in ways that are relevant for partnership and family formation today. This entails at least two things. First, given the increasing importance of unmarried cohabitation and given the fact that a growing proportion of children are born outside marriage in Europe (Sobotka and Toulemon 2008), the concept and idea of the marriage squeeze should be broadened to include the effects of age-specific sex ratio imbalances on the mating market rather than on the marriage market only. For the same reason, when I use the concept of homogamy in this paper, it is meant to refer to the pattern of assortative mating in unmarried cohabitation as well as in marriage. Second, and crucial for this paper, education should be added to the dimensions of age and sex to quantify the mating squeeze in a more meaningful way (Lutz et al. 1998). The expansion of higher education among women implies that women who want to find a male partner with the same or a higher level of educational attainment would increasingly suffer an educationspecific mating squeeze.

The concept of the marriage squeeze is particularly useful when seeking to explain changes that are opposite for men versus women (Oppenheimer 1988, 564). For example, when women suffer a marriage squeeze for a lack of suitable partners, the implication is that men would enjoy an abundant "supply" of potential partners. This may trigger potentially opposite changes for men and women. Or, from the perspective of couples rather than individual men and 
women, since a heterosexual match involves both a man and a woman, a shifting mating squeeze may have non-monotonic effects, for example on the pattern of assortative mating, on family size or on the risk of union dissolution.

\section{Figure 1:}

Sex ratios (men/women) for people aged 25-29 years old with a degree in tertiary education, European countries plus the US and Canada, 1970-2010 (log-scale)

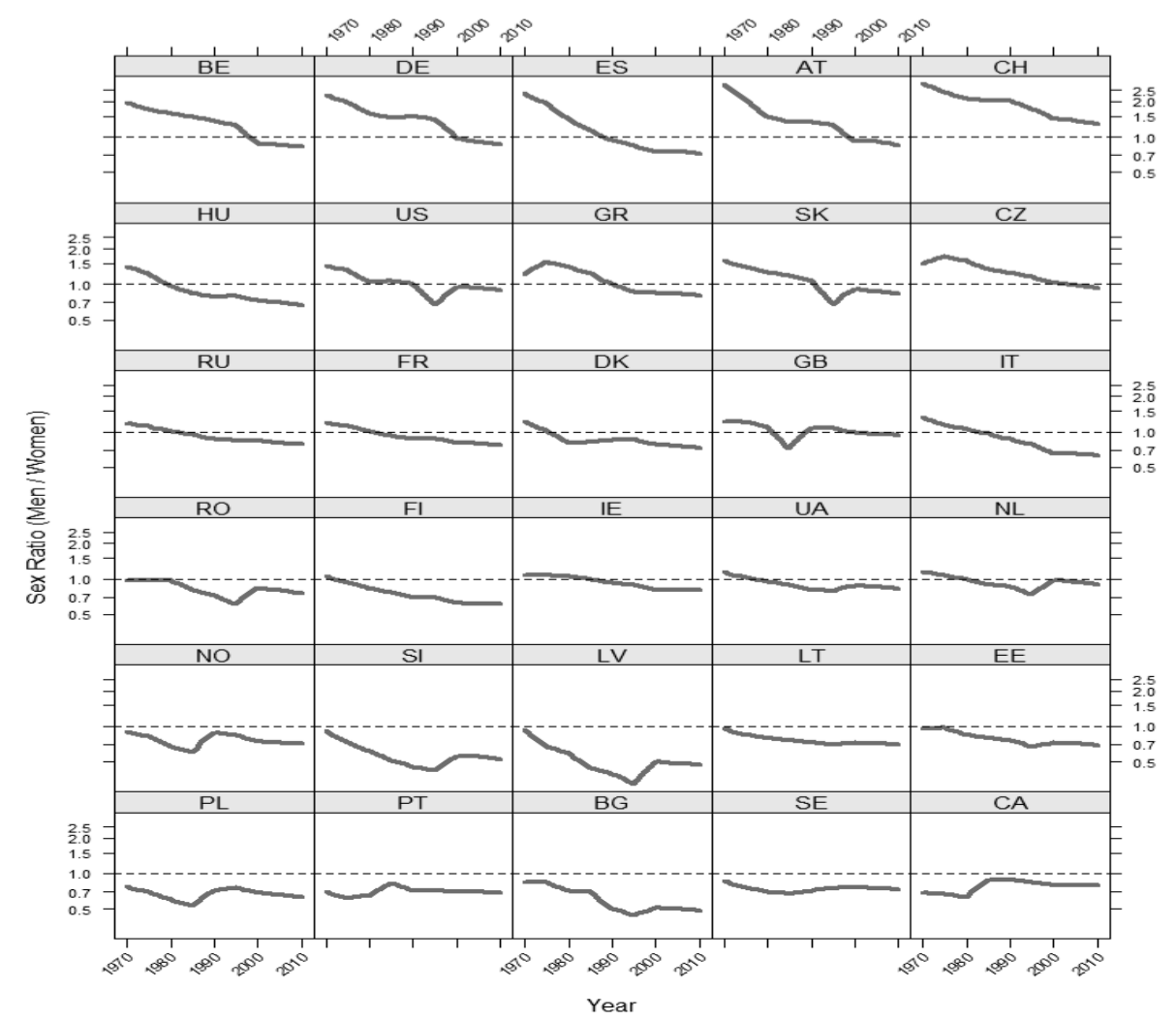

Ideally, measuring the extent of marriage squeeze entails reconstructing sex ratios by level of education at the reproductive ages for singles only. The required data to do this are not available right away for a large number of countries. However, as a first approximation, yearly sex ratios at the reproductive ages by level of education can be calculated based on the IIASA/VID education-specific population projections (Lutz et al. 2007; KC et al. 2010). Figure 1 plots yearly sex ratios at age 25 to 29 years for young adult men and women with a degree in tertiary education, covering the period 1970-2010 (figures beyond 2000 are based on the GET-scenario, see KC et al. 2010; yearly figures are linearly interpolated from five-yearly figures).

Countries that exhibited the most strongly skewed sex ratios for the highly educated back in the 1970s are in the top row of the figure. With sex ratios of 2.0 and higher in Belgium, Spain, Germany, Austria and Switzerland, highly 
educated men very clearly outnumbered highly educated women on the mating market in 1970; in Switzerland, for instance, there were over 280 highly educated men for each 100 highly educated women of age 25 to 29 years. In most countries, the sex ratio was much lower. In Hungary as well as in the US, for example, there were "only" 140 highly educated men for each group of 100 highly educated women. In France and Denmark, this number stood at 120, in Italy at 133 . According to these figures, there was already a female majority among 25-29 years old people with a tertiary degree in a surprisingly high number of countries. These countries tend to be situated in post-communist eastern Europe as well as in northern Europe.

The big general trend between 1970 and 2010 is one of declining sex ratios among the highly educated, such that by 2010, in all but one country (namely Switzerland), the sex ratio was below 1 . In countries that already had a low sex ratio in 1970, the decline tends to be more limited or even absent (like in Sweden); in countries with a high sex ratio, the decline tends to be more dramatic. In most cases, the decline was more or less monotonic, but there are a conspicuously large number of cases where the sex ratio went up for a couple of years after a previously declining trend (see the US, Slovakia, the Netherlands, Latvia, Romania, Poland and Norway). In all cases, this happened when the sex ratio was already below the threshold of gender parity, i.e. when women were already in the majority among young adult graduates. And in all cases, the declining trends towards an even stronger majority of women continued afterwards.

\subsection{Implications of an education-specific mating squeeze}

It will be highly important to investigate the origins of these national variations in the general trend towards an ever stronger majority of women with a degree in tertiary education. To the extent that they represent twists and turns that are exogenous with respect to reproductive behaviour, these variations provide statistical leverage for investigating the causal effect of the education-specific mating squeeze on reproductive behaviour. In order to address this issue, it will also be important to reconstruct sex ratios for singles. Sex ratios for singles are expected to be even more skewed than the ones presented here (Guttentag and Second 1983, 16-19). Sex ratios for singles are directly affected by mating and schooling behaviour, and they are hypothesised to affect such behaviour in turn.

The following sections discuss potential implications of an education-specific mating squeeze for reproductive behaviour. Figure 2 depicts the causal pathway that is assumed to be relevant and that is used to organise the discussion. First, RGIE and the ensuing mating squeeze are expected to affect patterns of assortative mating. Next, the degree of difficulty that men and women encounter in mating assortatively, is hypothesised to affect the probability, timing and stability of union formation. These trends and differentials are in turn expected to affect fertility. 
Figure 2:

Hypothesised implications of the shifting gender imbalance in education for reproductive behaviour

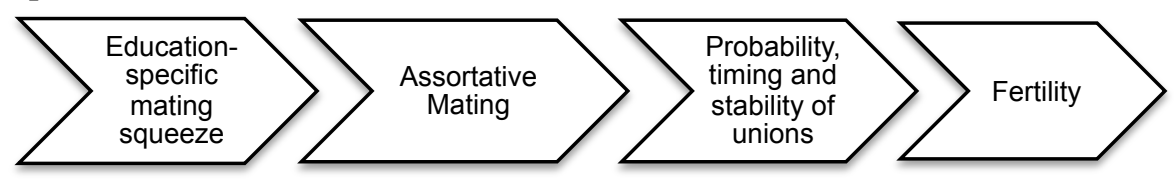

\section{Implications for assortative mating}

Understanding educational assortative mating is essential to understand the reproduction of social inequality in modern societies. Educational assortative mating is particularly important because (a) education is an important determinant of occupational success in modern societies and (b) education reflects cultural resources that influence an individual's preference for specific partner traits. "Educational homogamy implies that the degree of social inequality engendered in an individual's life course is further enhanced through marriage because advantageous (and disadvantageous) economic and sociocultural resources of two individuals are then pooled and cumulated" (Blossfeld 2009, 515). It has been clearly demonstrated how marriage levels and patterns by education have implications for the welfare of adults as well as children (Goldstein and Kenney 2001; McLanahan 2004), including their health (Huijts et al. 2010). It may therefore be expected that patterns of assortative mating will have implications for fertility as well, although very little research has been published about this issue (Huber and Fieder 2011).

If there are more highly educated women than men entering the dating and mating market, the old pattern of female educational hypergamy and male hypogamy can clearly not persist. One may envisage at least five "escape routes".

(1) The pattern of educational homogamy may become stronger to the expense of female hypergamy. However, this will not suffice to absorb the growing number of female graduates in the marriageable ages.

(2) A pattern of female educational hypogamy and male hypergamy may emerge, with men choosing a mate who is more highly educated and women mating men who received less education than themselves. In the popular media, this option has already been nicknamed "down-dating".

(3) Younger people may be more inclined to choose a partner from older generations: in older generations, young women may still find an excess stock of highly educated men, while young men, irrespective of their level of education, find more women with a lower level of education in older generations. In both cases, the implication is weakening age homogamy.

(4) People who do not find a suitable partner in the local marriage market may start to explore more distant marriage markets - more "distant" may be 
understood both in geographic terms and in ethnic terms. Strong geographic and ethnic endogamy having been the rule, RGIE may imply more exogamy in geographic and ethnic terms.

(5) A growing proportion of highly educated women may not be able to find a suitable partner and remain single. They may remain single for longer episodes or even throughout their whole adult lives.

Route (1) is perhaps the most obvious way to go. There are not only theoretical reasons to expect that educational homogamy should have increased during the past decades, but there is also empirical evidence supporting such a claim. The theoretical reasons have to do with structural opportunities to meet potential partners and with a shift of male mating preferences. First, the opportunities to meet a partner with the same qualifications are strongly dependent on the respective level of educational attainment. This follows from the fact that educational systems in the West involve a stepwise selection process: the intellectually less able and educationally disadvantaged are leaving the system at earlier ages, when the cohort is still heterogeneous in terms of the final level of educational attainment. The less educated enter the labour market as well as the marriage market at an earlier age. These earlier transitions are connected with more heterogeneous social networks and involve an increase in the frequency of contact with people with different social characteristics such as age, occupation or educational attainment. Therefore, for the less educated, the selection of a partner takes place in a more heterogeneous mating market. In contrast, for those who continue to go to school and university, the educational selection process generates increasingly homogeneous groups filtered in terms of educational qualification. The more highly educated continue to explore the mating market until a higher age while that market is increasingly filtered. The likelihood of educational homogamy therefore increases significantly with the level of educational attainment (Mare 1991). Empirical studies have indeed concluded that the degree of educational homogamy increases with the level of educational attainment (Blossfeld and Timm 2003). A logical implication of this mechanism is that the expansion of higher education produces higher levels of educational homogamy.

The second reason why educational homogamy is expected to increase relates to shifts in the mating preferences of men. It should be noted that not only women's level of education has strongly increased, but also their participation in the paid labour market and their earning potential (although not to the same extent as their level of education). As a result, to varying degrees, many Western countries have evolved from a male-breadwinner model to a dual-earner model. Gainful employment of wives and mothers has become accepted and expected in the younger cohorts and contributes to the social status of families (Beller 2009). As the wife's salary becomes an important determinant of the living standard and life style in dual-earner households, and as the level of education is a major determinant of a person's salary, it may be expected that men will increasingly 
prefer women with a degree in tertiary education. So, in more recent birth cohorts, men are expected to increasingly prefer a partner with higher qualifications (Mare 1991; Sweeney and Cancian 2004; Rose 2004; Dykstra and Poortman 2010). In sum: both the overall increase of female and male participation in higher education and the change in men's preferences are forces that are expected to raise the level of educational homogamy and to reduce the level of hypogamy and hypergamy of men and women, respectively. So far, the empirical evidence indeed suggests that educational homogamy has been on the rise (Blossfeld and Timm 2003).

However, evidence also indicates that a number of traditional gender role expectations remain strong, even in dual-earner societies. Gender role shifts have been asymmetric, because it turns out that women have been catching up more in terms of education and labour market participation than men have been catching up in their involvement in housework and child care (Blossfeld and Drobnič 2001). From the perspective of "doing gender" (West and Zimmerman 1987), there continue to be a number of normative pressures for men to behave traditionally and stereotypically like "a real man" and for women "like a real woman". The asymmetric and incomplete gender role change may help to explain the empirical finding that the proportion of women marrying men who are less qualified than themselves remains much lower than could be expected from an egalitarian point of view (Blossfeld and Timm 2003). Yet it is too early to draw any firm conclusions on this since we are dealing with quite recent changes, at least in some countries. It remains to be investigated whether the preference structure underlying female educational hypergamy is on its way to weaken or even dissolve. Recently, Esteve et al. (2011) explicitly showed that female hypergamy is lower in societies with a lower gender gap in education. Their analysis suggests that it is really the mating squeeze that is driving the shifts in behaviour (i.e. a shortage of highly educated men), rather than a shift in the preference structure. There is also evidence of a recent decline of female hypergamy in the US at the top of the social ladder, but at the same time, hypergamy seems to be becoming stronger at the bottom of the same ladder (Rose 2004). Recent exploratory work suggests that women even today are very reluctant to contact men with less educational qualifications than themselves, whereas men are still likely to contact women with lower educational degrees (Blossfeld 2009). This points to a persistence of traditional gender preferences.

Also indicative of such persistence is the fact that the choice of study subject remains strongly gender-based. For example, women are more likely to study subjects related to health, teaching and the social sector; men are more likely to choose sectors like engineering and business economics. Gender wage differences are partly attributable to the subjects that men versus women choose to study (Bradley 2000; Charles and Bradley 2002), and it has been shown that this kind of gender segregation also affects demographic behaviour (Van Bavel 2010). While educational gender segregation by subject has probably declined somewhat over 
the past decades, it has remained quite stable in recent years, and the feminisation of higher education in general has exacerbated the gender segregation of already highly feminised disciplines like health, services and education (Vincent-Lancrin 2008).

The educational segregation by study subject is often portrayed as "horizontal", in contrast to the "vertical" segregation by level of educational attainment. However, as different types of study subject lead to divergent levels of salaries, these may also correlate with divergent levels of prestige and social standing. It has been observed in the past that an increasing proportion of women entering a profession over time was related to a decreased rating of the social prestige of that profession (Wilson and Boldizar 1990). Thus, if female university graduates outnumber male graduates, it remains to be seen to what extent existing patterns of female hypergamy and male hypogamy persist through the genderbased choice of study subject. In other words, apparently increasing homogamy (Escape route (1) may hide persistent female hypergamy in terms of the implied economic status and social standing.

There is convincing evidence that Escape route (2) is becoming relevant when the gender balance in education reverses: Esteve et al. (2011) recently showed that in populations with a reversed gender gap in higher education, female educational hypogamy starts to exceed female hypergamy. In other words, in countries with more women than men completing a degree in tertiary education, there are more women marrying downwards in terms of level of educational attainment than there are women marrying upwards. This finding is based on large IPUMS (Integrated Public Use Microdata Series) samples and holds not just for European countries like France, Greece, Italy, Portugal, Slovenia and Spain, but also for the US, Argentina, Brazil and Venezuela in the Americas, as well as for Israel and the Philippines in Asia.

In sum, the following hypothesis can be formulated based on the literature on educational assortative mating: RGIE will not only strengthen educational homogamy but will also imply that the traditional patterns of female educational hypergamy are increasingly replaced by female educational hypogamy, which creates an increasing proportion of couples where the wife is more highly educated than the husband (Hypothesis 1.1).

Next, referring to Route (3), an often neglected phenomenon, highly relevant for the pattern of educational assortative mating, is the issue of age homogamy. The rise of age homogamy, i.e. the situation where people choose a partner of about the same age, is considered a hallmark of the rise of a less instrumental and more egalitarian partner selection process. One factor that helped husbands maintain control over their wives in the past was the fact that they tended to be considerably older than their wives. A large age difference gave the husband a considerable advantage in status, experience and power. Over the course of the 19th and 20th century, the age difference declined towards about two years, on 
average, reflecting a more egalitarian attitude towards mate selection (Van de Putte et al. 2009).

Age homogamy tends to be particularly strong among the highly educated (Blossfeld 2009). This is related to the fact that having finished education is, in most modern societies, an important precondition for family formation. More highly educated persons take longer to meet this precondition but after finishing education they tend to quickly catch up with their age cohort and soon marry or start cohabiting. In contrast, the less educated enter the labour and marriage market at an earlier age. These earlier transitions are connected, as has been mentioned, with more heterogeneous social networks and imply an increase in the frequency of contact with people with different social characteristics, including age. Therefore, for the less educated, marriage behaviour is less age-graded, and age heterogamy is more likely.

The question here is: given the current trend towards women being better educated than men, what will happen with age homogamy? The expectation is that RGIE will weaken the modern pattern of age homogamy: while the average age difference between heterosexual partners is now about two years, this age difference is expected to increase, with men typically being the older partner (Hypothesis 1.2). We will also have to see how this would interact with the pattern of female hypergamy and male hypogamy in the socio-economic dimension. If highly educated women do not find enough highly educated men of about the same age, they may turn towards older (possibly divorced) men: in older cohorts, highly educated men still outnumber highly educated women considerably (Vincent-Lancrin 2008). This process may undermine egalitarian power relationships within couples, as a mirror image of the past trend described by Van de Putte et al. (2009). If so, the fact that highly educated men are becoming relatively scarce will doubly undermine the equality of power between men and women: first, because of their mere scarcity, highly educated men can afford to be more picky than before; second, if highly educated women from younger generations are turning towards older cohorts of men to find a reservoir of suitably educated men, the age difference will rise, again potentially favouring male dominance.

Increasing geographic and ethnic exogamy represent Escape route (4): people who do not find a suitable partner in the local marriage market may start to explore more distant marriage markets. Much more than has been done in previous research about assortative mating, we will have to take migration into account. The literature about the marriage squeeze acknowledges that migration flows can be an important cause of imbalanced sex ratios (Guttentag and Secord 1983, 17; Angrist 2002). In the coming years, I expect that we will increasingly see a connection the other way around, with RGIE giving rise to migration flows that are at least partly motivated by mate searching.

In recent decades, many Western countries have seen an increase in the number of bi-national marriages and marriage-related migration (Kofman 2004; 
Timmerman 2008; Beck-Gernsheim 2011). For Belgium in the late 20th century, it has been found that the correlation between education and the probability to marry an "imported" spouse differs by gender: highly educated men were less likely to marry immigrant women, while highly educated women more often married immigrant men (Lievens 1999). At the same time, studies have found that educational homogamy persists both in case of marriage migration as well as in the case of interethnic marriages (Kalmijn 1993; Lievens 1999; Çelikaksoy et al. 2006). This raises the following questions: to what extent can the recent rise in marriage migration be explained by a mismatch between the educational distributions of men and women among ethnic minorities? To what extent are education-specific marriage squeezes conducive to changing rates of intermarriage along ethnic dimensions? The educational gender gap in favour of women, as observed in recent years, tends to be even more pronounced among ethnic minorities (Vincent-Lancrin 2008; Buchmann et al. 2008). Given the fact that success in higher education among men in ethnic minorities is relatively low, mating and marriage prospects for these men may be particularly poor. This may further stimulate marriage migration. In sum, the hypothesis is that RGIE will stimulate geographic and ethnic exogamy: it will stimulate mating between partners from different ethnic groups in a given population and it will also stimulate marriage migration (Hypothesis 1.3).

\section{Probability, timing and stability of union formation}

In recent decades, the proportion of women who never marry has been on the rise in Europe. Marriages have been increasingly postponed and unmarried cohabitation has strongly gained ground (Sobotka and Toulemon 2008). To what extent are shifts in higher education driving these trends? From a macro perspective, there is a positive rather than a negative correlation between educational expansion and marriage in Europe: the higher the enrolment rate in tertiary education, the higher the marriage rate at the country level — and also the higher the rate of unmarried cohabitation and divorce (Kalmijn 2007). It is far from clear, however, what this implies for individual-level rates of union formation and dissolution.

\subsection{Union formation}

With respect to the likelihood of marriage, the most influential hypothesis holds that women with many socio-economic resources are less likely to marry than women with fewer resources. In contrast, men with more resources are expected to be more likely to marry than less well-off men (Dykstra and Poortman 2010; Jalovaara 2012). From the perspective of gender roles and division of labour in the male-breadwinner/female-homemaker family model, it has indeed been argued that highly educated women would be less prone to marry because their 
education has given them the human capital resources to be independent. From the perspective of (some, high income) male breadwinners, highly educated women may be considered less attractive because they may be less inclined to abide by the role expectations for female homemakers. This has been the classic rationale for expecting lower marriage rates for highly educated women (Blossfeld 2009).

The implication of this view is that RGIE would lead to worsening marriage prospects for more educated women as well as for less educated men, notably when the traditional pattern of assortative mating persists. However, research in the US has found no decline of marriage probabilities among more highly educated women and indicates that unmarried cohabitation has not at all replaced marriage, especially not among the highly educated. In the US, it appears that a decline in hypergamy allowed the marriage market to absorb the increased number of educated women (Rose 2004). The increased earning potential of American women is associated with later ages at marriage, but not with lower marriage chances. In contrast to earlier time periods, marriage is now more likely among the college graduates than among the less educated (Goldstein and Kenney 2001; Isen and Stevenson 2010), hinting at the possibility that marriage may become "a province of the most educated", which may contribute to further social inequality (Goldstein and Kenney 2001; Gibson-Davis 2009). Even in a highly developed welfare state like Norway, Kravdal (1999) has found that people who are economically better off are more likely to convert unmarried cohabitation into marriage. A recent study in Finland presents findings that are consistent with the conclusion for Norway (Jalovaara 2012).

Most research confirms that men with higher socio-economic status exhibit higher marriage rates than men with lower status, in line with theoretical expectations (Jalovaara 2012). Unexpected and remarkable, however, was the very recent finding that university-educated men in the Netherlands are more likely to remain single. Research results about the marriage prospects of recent cohorts of women, differentiated by level of education, are even more mixed. A number of studies do not find the expected negative effect of women's socioeconomic status on marriage rates (Dykstra and Poortman 2010; Jalovaara 2012).

Overall, the recent literature about the educational gradient in union formation has reported inconsistent and unexpected findings, particularly for women. This may have to do with the fact that the literature has insufficiently distinguished between two components underlying cohabitation as well as marriage rates: the probability of ever making the transition on the one hand and the timing of the transition on the other hand. Although the two components are clearly related, trends in both components need not necessarily go in the same direction. RGIE may have diverging effects on the likelihood and on the speed of union formation.

Oppenheimer (1988) explicitly links the timing of marriage to assortative mating. Her theory of marriage timing argues that trends and differentials in marriage timing are affected by the degree of difficulty that people encounter in 
mating assortatively. From that perspective, RGIE and the ensuing new education-specific mating squeeze can be expected to have a different impact on women and men. For simplicity's sake, the following speculations on this issue do not distinguish between unmarried cohabitation and formal marriage. However, in concrete empirical research, it is advisable to take into account how unmarried cohabitation and marriage may be almost equivalent institutions in some European regions while they are very different in other regions; in some countries, unmarried cohabitation is usually a prelude to marriage, in others it is more a full-fledged alternative (Rindfuss and VandenHeuvel 1990; Kravdal 1999). Also, to simplify the discussion, we distinguish between highly educated and relatively little-educated men and women, without considering the implications of a more nuanced system of stratification in educational attainment.

I first consider highly educated people. As pointed out by Oppenheimer (1988), mating depends both on availability of suitable partners and on the information about potential partners. With increasing age, the availability declines while information and knowledge increases. So, for them, "to wait or not to wait" is the question. Women in colleges and on university campuses may increasingly perceive the shortage of men among their peers. Women who are looking for a partner may increasingly (with age as well as cohort) fear to be "left over" and some may therefore be prepared to accept a match earlier. Women who were not prepared to accept an early match may face a growing difficulty to find a suitable partner, and some may decide not to step into a relationship anyway. Therefore I expect a growing statistical polarisation between on the one hand a group of women who will more quickly enter a union and on the other hand a group of women who will never enter a union, or only at a more advanced age. In other words, I expect that the distribution of waiting time to union formation will have a stronger concentration at relatively young ages but a longer tail as a consequence of rapidly declining marriage rates afterwards. If anything, the proportion of highly educated women never entering a union could be expected to go up in most European countries. Men with high education generally have the best mating prospects. They see an abundance of women with an equal level of education. As a result, they are in a position to raise their standards, experiment more with several subsequent relationships, and wait longer to accept a match. As a result, I expect much less polarisation than in the female case. For men, I rather expect a more bell-shaped distribution of waiting times to forming a union: there will be some early and some late birds, with the bulk of men falling in between, with the average and median age about what it is today.

Summing up, Hypothesis 2.1 is that RGIE will create a growing statistical polarisation among highly educated women between the ones who enter a union at a relatively young age on the one hand, and another group of women who never enter a union, or only at a very advanced age. The distribution will be markedly different for highly educated men, who are expected to exhibit a more bell-shaped 
distribution of waiting times to union formation and declining proportions remaining single.

What about people with a lower level of education? The traditional pattern of female hypergamy implied a lower level of education for wives than for husbands. This suggest that women with a relatively low level of education would be attractive partners, not just for men with a relatively low level of education but also for highly educated men with an inclination to pair off with a "housewife". However, the woman's level of education has become a much more important determinant of a household's living standards in recent decades. If anything, this would suggest that an increasing proportion of men would tend to prefer a highly educated partner. Esteve et al. (2011) even present evidence suggesting that, when the gender imbalance in education turns around, so does the social preference for female hypergamy and male hypogamy as well.

All in all, my hypothesis is that less educated women will have high prospects for union formation; I expect that this group will exhibit the lowest ages at union formation as well as the lowest proportions never entering a union. The rationale for this hypothesis is that female hypergamy is traditionally expected and accepted (even while educational homogamy has become dominant), which implies that the pool of potential partners for relatively little-educated women includes not just (abundantly available) less educated but also (more scarcely available) highly educated men. The mating prospects for less educated men, in contrast, are expected to be the lowest. Indeed, a growing proportion of their female age peers is completing a degree in higher education. This implies that there are fewer equally less educated women available for dating and mating while the more highly educated women are expected to prefer an at least equally educated man. Therefore, I expect increasing ages at union formation and a growing proportion never entering a stable union among less educated men.

Summing up, Hypothesis 2.2 is that while less educated women will (continue to) have the lowest ages at union formation as well the lowest proportions never entering a union, less educated men will exhibit increasing ages at union formation as well as growing proportions never entering a union. One can speculate about the implications of this predicament for gender role behaviour. Since there are not enough less educated women available to match the numbers of less educated men, and since there are not enough highly educated men available to match the numbers of highly educated women, relatively lesser educated men may want to try ways to increase their attractiveness for highly educated women. One way to do this could be to take a larger share in tasks and jobs that traditionally were part of women's role, like cooking, house cleaning and child minding - which could also be the more attractive division of labour from the household economics point of view when the wife's salary exceeds that of the husband. This leads to Hypothesis 2.3: less educated men can enhance their chances at getting together with highly educated women by doing a larger share in child care and household chores. In this way, the gender role implication of RGIE 
for less educated men mirrors the gender role change implied by women's growing participation in higher education.

\subsection{Union dissolution}

As stated in the previous section, if there are "too many women" in some particular marriage market and "too few men" (as is increasingly the case among the highly educated), men have more alternatives if they are not satisfied with their current partnership than women. Not only can they be more picky when entering a partnership but they can also more easily leave an existing one. Alternatively, from the female perspective, given a shortage of suitable men, women may be inclined to accept a partner as reasonable more rapidly and run into marriage earlier, but they may regret it later and be more inclined to separate, especially if they have got the resources (including education) to cope all by themselves. Earlier studies have indeed documented that a shortage of men relative to women is associated with higher rates of divorce (Lichter et al. 1992; South et al. 2001), but these studies did not specify the mating squeeze by level of educational attainment.

While divorce rates are higher in countries with more highly educated people (Kalmijn 2007), there are many countries where divorce rates for the highly educated are lower than for less educated people. A case in point is the US, where the education of both spouses is negatively associated with divorce (Amato 2010). In Europe, the educational gradient depends on the country and has changed over time. Generally speaking, it appears that education and divorce are positively correlated where and when marital dissolution is relatively uncommon and the social and economic costs involved are high. There tends to be no or a negative relationship between the level of educational attainment and divorce risks when marital dissolution is relatively common and the costs are low (Härkonen and Dronkers 2006; de Graaf and Kalmijn 2006; Amato and James 2010).

There are several reasons for expecting that the pattern of assortative mating as well as the education-specific mating squeeze are relevant for union stability. First, there are indications that woman's downward marriage (i.e. female hypogamy, including unmarried cohabitation) increases divorce and separation rates (Blossfeld 2009). Since this type of female hypogamy is expected to increase as a consequence of the new education-specific mating squeeze (Esteve et al. 2011), divorce rates may be expected to go up.

The extent to which union dissolution has adverse consequences for men and women will depend not only on potential alternatives, as indicated above, but also on the amount of resources held independently by the former partners (Amato 2000), and this will depend, in turn, on the pattern of assortative or nonassortative mating, i.e. on the specific mix of his and her education. For example, women who are more educated than their (former) partners may have more bargaining power to negotiate better arrangements during the divorce process. This makes them less vulnerable and gives them an advantage on top of the direct 
economic value of their human capital in the labour market. The higher human capital held by women with more education gives them more degrees of freedom to leave unhappy unions. This may explain the higher divorce rates for highly educated women in countries were divorce is relatively uncommon and where the social and economic costs of divorce are relatively high (Härkonen and Dronkers 2006; Amato and James 2010). Still, in countries where divorce is generally more common - and where female participation in tertiary education is typically very high - the connection between a woman's level of education and the risk of union dissolution tends to be negative. However, at least in the case of the US, the apparent "divorce-prohibiting effect" of education was found to be achieved indirectly through assortative mating, i.e. via the greater chance of highly educated women to marry a highly educated men - and highly educated American men are less likely to divorce than less educated men. In contrast to the divorceprohibiting indirect effect of prolonged education through homogamy, the direct effect of high education on the divorce risk was found to be positive for American women. But the indirect divorce-inhibiting effect of women's education via assortative mating appears to be larger than the divorce-enhancing effect of women's education (Teachman 2002). Summing up, RGIE is expected to affect divorce rates indirectly: it is expected to make female educational hypogamy more common, and hypogamous unions are expected to be less stable. On the other hand, a divorce-prohibiting effect is expected to the extent that RGIE leads to increasing educational homogamy, as homogamous unions are expected to be the more stable ones (Hypothesis 2.4). There is a caveat, however: we will have to see to what extent the latter divorce-prohibiting effect holds in the context of the new education-specific mating squeeze. Guttentag and Secord (1983: 20) argued that if sex ratios in the reproductive ages are low, i.e. when there is an excess of women in the mating market, then divorce rates as well as repartnering rates for men may be expected to increase, while repartnering rates for women will go down. Applied to education-specific sex ratios, the union dissolution rates for the more highly educated should be expected to go up, even for educationally homogamous unions, since highly educated men have more options to repartner with an equally educated woman. To repeat a point made when discussing age homogramy: especially among younger cohorts of women, there is an abundance of potential partners for the highly educated.

Often, repartnering can help people to overcome some or all of the difficulties in divorce and separation (Dewilde and Uunk 2008) but at the same time, new challenges may arise after repartnering, such as conflicts between the new partner and the children (de Graaf and Kalmijn 2003). Even if repartnering rates have important implications for the well-being of the growing ever-divorced population (Soons et al. 2009), the number of studies about the determinants of repartnering remains small. Most of the existing studies address remarriage, not unmarried cohabitation. We know that men are much more likely to repartner than women. Also, there is a consistent finding that older people more often remain single than 
younger people (de Graaf and Kalmijn 2003). But we know little about the educational mix of higher-order unions (i.e. relationships formed after a divorce or separation). Are they more often homo- or heterogamous than first unions? One American study shows that high-status men tend to remarry less-educated, young women and that both educational and age homogamy is less likely for both men and women in higher-order unions, regardless of their initial socio-economic status (Shafer 2009). Hypothesis 2.5 is that we will see the same happening in Europe: higher-order unions, constituted after divorce and separation, are expected to conform more to the traditional pattern of female educational hypergamy than first unions. Since men have higher repartnering rates than women, this hypothesis is particularly relevant for men's higher-order unions.

\section{Consequences for fertility}

It is well known that the expansion of female participation in higher education has been a major reason for the most important European fertility trend of the past decades, i.e. the postponement of parenthood and the ensuing decline of period fertility towards very low levels (Sobotka 2004; Billari and Kohler 2004). Dozens of studies have documented how women's education affects the timing of fertility, but surprisingly little is known about the relationship between education and the quantum of completed cohort fertility. We know even less about the trend in this relationship over time (Kravdal and Rindfuss 2008), let alone about how this may be related to RGIE. The literature about the timing of first births has paid too little attention to the dynamics of assortative mating and union formation.

One of the few observations that have been made quite consistently about fertility quantum is that highly educated women have tended to remain childless more often than less educated women, while the reverse has usually been observed for men (Kravdal and Rindfuss 2008). But we hardly know anything about what happens when he as well as she is highly educated; is such a couple more likely or less likely to remain childless? Is his level of education of determining importance for family size, or is it rather hers? And what about completed family size for couples who do not remain childless? Despite the large number of studies about education and fertility, only few studies have applied a couple's perspective (e.g. Thomson et al. 1990; Corijn et al. 1996; Köppen 2006; Rosina and Testa 2009). Studies addressing the relation between homogamy, hypogamy or hypergamy on the one hand and fertility on the other hand are still lacking, with very few exceptions (Corijn et al. 1996; Bauer and Jacob 2009; Huber and Fieder 2011).

\subsection{Assortative mating and reproductive decision making}

Most fertility studies and surveys are women-only. This practice is based on the assumption that (a) female and male partners share the same conditions of life and 
will therefore go for the same number of children, (b) since it is women who bear children and are the primary caregivers, their perspectives are decisive for fertility, and (c) women's intentions incorporate those of their partners, reflecting resolution in case of initial disagreement. However, data collected from couples consistently show that substantial proportions of couples disagree about the preferred family size. This kind of couple disagreement has been shown to be a primary source of gaps between fertility desires on the one hand and intended and actual fertility on the other hand (Thomson 2001; Voas 2004). We have hardly begun to investigate how this may be related to assortative mating. One study about the effect of assortative mating on fertility was carried out with British data by Mascie-Taylor (1986). He found that educationally homogamous couples had more children than educationally heterogamous ones. The data refer to families formed in the 1950s and 1960s, however, when the male-breadwinner/femalehomemaker family model was stronger than today, and female participation in higher education much lower. Huber and Fieder (2011), using US 1980 census data, show that the proportion of childless women is usually minimal for those married to a husband of the same educational level. This finding holds particularly true both for most highly and least educated women. The reasons for these empirical results remain unexplained, however.

A common thesis in research on assortative mating is that homogamous couples are more likely to show value consensus than heterogamous couples. Homogamy is argued to facilitate understanding between partners, resulting more often in shared goals (Thomson 1990). Also, partners in homogamous couples are more likely to have similar lifestyles (Kalmijn 1991a). Whether or not this may explain higher fertility for homogamous couples depends on what these "shared goals" and "similar lifestyles" entail, and on how decisions are made in case of disagreement about fertility matters. Several decision-making strategies or rules can be discerned. One is the patriarchal strategy, where men have the final say. Another is the spheres-of-interest strategy, where decisions about childbearing are left to women on the argument that these are female matters. Other strategies follow the inertia or the egalitarian rule, for example (see discussion in Thomson 1990 and Corijn et al. 1996). Strategies like this may be more or less relevant in particular historical contexts.

Particularly relevant from the perspective of the gender imbalance in education is the power rule of decision making, where fertility decisions depend on the partners' relative resources: the most powerful partner has the final say. An American study (cited in Corijn et al. 1996) reported supporting evidence for this rule, because the influence of the wife on completed fertility among Hispanics was higher the more educated she was. I think it is crucial, however, to put this finding in its context of a gender imbalance in education that is strongly in favour of men. Below I argue that the implications of being highly educated for the power relationships within a couple can be expected to be completely different when there are more women than men with high education. For Europe, a relevant 
recent finding is that a lack of agreement in reproductive decision-making among Italian couples is likely to occur where the role of the woman is less traditional. In particular, highly educated women are more likely to be in disagreement with their partners about fertility matters (Rosina and Testa 2009).

From an earlier study, it was concluded that whether his or her level of education weighs more heavily on actual fertility depends very much on the social context (Corijn et al. 1996). To date, we still lack studies with a broad European scope addressing these issues. I argue that RGIE has a double relevance for the current and future course of fertility in Europe. First, through its effect on assortative mating, it is affecting, and will continue to affect, power relations within couples at the micro level. Second, the move towards more women than men with higher education may bring more women to power in public institutions and in the economy. I expect that this will change the macro-social context of childbearing (for example in terms of institutional provisions for child care, see Van Bavel and Różańska-Putek 2010).

First, at the micro-level, the first implication of RGIE to think about is that more often than in the past, the woman's income will be more important for the household than the husband's. This is particularly expected to happen in case of female educational hypogamy and represents another reason for expecting that gender roles may shift especially for less educated men toward a higher involvement in child care and household chores-in Section 5.1 (Hypothesis 2.3) I already argued that less educated men could enhance their attractiveness for highly educated women by doing a larger share of domestic work than traditionally expected. To the extent that this implies that women more often become the chief breadwinner of the household, the expected effect on fertility could be negative at first sight, when the opportunity costs of childbearing are assumed to increase with the mother's salary. However, an important indirect consequence of RGIE could be that such an assumption becomes less and less warranted. Indeed, to the extent that the husband actually takes on the role of chief homemaker and child minder, the opportunity costs of childbearing may actually be going down for a growing number of highly educated women, when they are no longer expected to give up their careers after childbirth.

Within homogamous couples with high education, the fact that there are more highly educated women than highly educated men may paradoxically push the balance of power more towards the advantage of men. If there are "too many women" in some particular marriage market and "too few men" (as is increasingly the case among the highly educated), men, not women, have alternatives if they are not satisfied with their current partnership situation. So it is men who can be more picky and who can more easily leave an old partner to choose a new one. Given a shortage of suitable men, women may be inclined to more rapidly accept a partner as reasonable and run into marriage earlier (South et al. 2001). This leads to three hypotheses. (A) Given that research has shown that a shortage of men relative to women in local marriage markets is associated with 
higher rates of extra-marital childbearing (South et al. 2001; Harknett 2008), it may be expected that extra-marital childbearing will increase among highly educated women. More particularly, I expect an increase of childbearing outside the context of stable partnerships, both by highly educated women who cannot find a suitable partner and by women who were abandoned by their previous partner. (B) For the same reason, it may also be expected that childlessness will increase. (C) With respect to the fertility decision-making process within a couple, RGIE would imply that men will be more able to impose their will upon more highly educated women. I expect that male preferences and characteristics will show up as becoming more decisive for fertility patterns in the coming years.

Second, at the macro level, RGIE may be expected to bring more women to power in politics and the economy. So far, however, the increase in the number of women holding a powerful decision-making position has been limited; "power is still firmly in men's hand in the political and economic spheres" (European Commission 2010: 9). The inconsistent development of gender equity in different societal institutions has been described as a key factor explaining very low fertility in Europe (McDonald 2000). In line with that hypothesis is the recent finding that further developments of gender equality are playing a key part in the recent revival of fertility in Europe, observed at high levels of human development (Myrskylä et al. 2009; 2011).

"If the imbalance in the relationship between the sexes continues for an extended period of time, an appreciable number of individuals from the gender lacking dyadic power may well get together and organise various types of actions to correct the situation. Thus, consciousness-raising groups might result, whose aim is to change the norms pertaining to relationships between men and women" (Guttentag and Secord 1983: 23). In line with this idea, I expect that imbalances of the sex ratio among the more highly educated to the advantage of women speed up the development of gender equity in politics and business. Further down the road, it is reasonable to expect that institutions and companies in Europe will become more adapted to combining work and family life, stimulating a further revival of fertility in Europe.

\subsection{Implications for fertility behaviour}

Since they have been argued to depend on future trends in assortative mating and union formation, the hypotheses about the fertility implications of the gender reversal are necessarily more conjectural. To summarise, we go back to Routes (1) to (5), discussed in Section 4 as potential responses to RGIE. It remains to be seen what Response(1), increasing homogamy at the expense of female hypergamy, will imply for fertility. There are hints in the literature that educationally homogamous couples tend to have more children than heterogamous couples, but the number of empirical studies documenting this is limited. Anyway, Hypothesis 3.1 is as follows: to the extent that RGIE translates into stronger educational homogamy, fertility is expected to increase. 
Route number (2), i.e. a switch from women mating upwards to women marrying downwards in terms of level of education, runs against traditional gender role expectations. Men in such couples may more than before define their fatherhood in terms of caring for children. Thus, among these femalehypogamous couples, a new definition of fatherhood may be expected to gain ground. If this implies a more equal division of labour within the home, there may be a fertility-stimulating effect, as discussed in the previous section. A study in the US suggested that there is a U-shaped relationship between fertility and gender equity in housework. In the study, second-birth rates were found to be relatively high both in the case of a traditional division of labour (women assuming almost all of the housework but not working for pay outside the home) and in the case of a non-traditional division of labour (with men doing a large share of the housework); the second-birth rates were lowest for double-burden women working outside the home while at the same time doing most of child care and household chores (Torr and Short 2004). Similarly, Cooke (2009) found that among the youngest cohorts of Italian couples, fertility is higher when the father takes up a larger share of child care, especially among employed women. She reported a similar finding for Germany: second-birth rates are higher when the husband does a fair share of child care. In the German case, increasing the husbands' share in housework was also associated with increasing divorce risks among childless German couples (Cooke 2004). The latter findings again hint at non-monotonic, countervailing implications. This leads to the double-edged Hypothesis 3.2: to the extent that RGIE translates into growing female hypogamy (replacing the traditional female hypergamy), countervailing mechanisms are expected to operate. On the one hand, a fertility-enhancing effect is expected for stable couples if the relatively little-educated husband assumes a fair share of housework and child care. On the other hand, female hypogamy may translate in union instability for other couples, with a negative effect on fertility, all else being equal.

Route (3), i.e. increasing geographic and ethnic exogamy, is also associated with higher union instability, which provokes Hypothesis 3.3: to the extent that RGIE translates in increasing geographic and ethnic exogamy and age heterogamy, it will negatively affect union stability, thus also negatively affecting fertility.

Route (4), rising age heterogamy may imply higher (multipartner) fertility for men, when it comes in the form of older men mating younger women and thus potentially prolongs the reproductive life stage for these men. For women, however, the effect of age heterogamy as such is expected to be neutral or even negative: negative to the extent that an older male partner implies lower fertility than a younger one (Goldman and Montgomery 1989; Matorras et al. 2011) or to the extent that rising age heterogamy is associated with higher union instability, since for women, union dissolution is unequivocally associated with lower fertility in Europe (Van Bavel et al. 2012). To the extent that rising age 
heterogamy is one of the responses to RGIE, I therefore expect that it will have a negative effect on the birth rate, because it is female, not male fertility that matters for the birth rate.

Finally, response Route number (5), i.e. increasing proportions remaining single, also implies lower female fertility. Hypothesis 3.4 is that, as a consequence of growing proportions remaining single, a growing proportion of highly educated women is expected to remain childless. At the same time, if a growing number of highly educated women with a desire to have children were to remain single, it may be expected that childbearing outside the context of stable relationships will increase somewhat. Until now, childbearing outside marriage or relatively stable cohabitation is largely limited to less educated women. To the extent that Route (5) is taken by women with a childbearing desire, this could change during the next years. Therefore, Hypothesis 3.5 is that childbearing outside the context of a stable relationship will become more common among highly educated women than it is today.

Finally, given the implications of RGIE for power relations between sexual partners at the micro level, as discussed in the previous section, I expect that male preferences and characteristics will show up as becoming more decisive for fertility patterns in the coming years (Hypothesis 3.6). At the macro level, RGIE may be expected to bring more women to power in politics and the economy, which may help making institutions and companies more adapted to combining work and family life. This is expected to exert a fertility-stimulating effect (Hypothesis 3.7).

\section{Conclusion}

Until deep into the 20th century, the proportion of men graduating from tertiary education was much higher than the proportion of graduating women. This gender imbalance has completely turned around so that today in almost all European countries as well as in the United States and Canada, and also in many other countries, women are clearly in the majority among the highly educated. The central hypothesis of this paper is that the reversal of the gender imbalance in higher education will have profound consequences for long-standing patterns of reproduction. More specifically, I expect the following causal chain between the reversal of the gender imbalance in education on the left hand side and fertility on the right hand side shown in Figure 2: this reversal creates a new, educationspecific mating squeeze that affects the process and expected pattern of assortative mating, which in turns affects the timing, probability and stability of union formation, with implications for fertility.

To summarise the discussion and arguments, this paper has formulated and numbered a series of testable hypotheses. The first set of hypotheses (1.1 to 1.3) are about the implications of the education-specific mating squeeze for assortative 
mating. The second set of hypotheses (2.1 to 2.5 ) are about the implications for the timing, likelihood and stability of unions. To simplify the discussion, I have neglected the distinction between unmarried cohabitation and formal marriage in this paper. Since the distinction remains sociologically and demographically meaningful, actual empirical work will have to refine these hypotheses, taking into account that the distinction between marriage and cohabitation signifies different things in different countries. The final set of hypotheses (3.1 to 3.7) are about the implications of the previous links in the chain for fertility.

Since all formulated hypotheses are testable, they are also falsifiable. They are inspired and motivated by current patterns of reproductive behaviour. No doubt, many of them will have to be rejected in the coming years since the assumed patterns will change in ways that cannot be foreseen today. But even so, I argue that explicitly stating what the expectations are based on current knowledge is a useful act to guide future empirical research and theory building because it will help identifying the gaps in our empirical knowledge and flaws in our theories.

\section{References}

Amato, P.R. 2000. "The consequences of divorce for adults and children." Journal of Marriage and the Family 62(4): 1269-1287.

Amato, P.R. 2010. "Research on divorce: continuing trends and new developments." Journal of Marriage and Family 72(3): 650-666.

Amato, P.R. and S. James. 2010. "Divorce in Europe and the United States: commonalities and differences across nations." Family Science 1(1): 2-13.

Angrist, J.D. 2002. "How do sex ratios affect marriage and labor markets? Evidence from America's second generation." Quarterly Journal of Economics 117(3): 997-1038.

Bauer, G. and M. Jacob. 2009. The Influence of Partners' Education on Family Formation. Mannheim: University of Mannheim. (Equalsoc working paper 2009(4)).

Beck-Gernsheim, E. 2011. "The marriage route to migration: of border artists, transnational matchmaking and imported spouses." Nordic Journal of Migration Research 1(2): 60-68.

Beller, E. 2009. "Bringing intergenerational social mobility research into the twenty-first century: why mothers matter." American Sociological Review 74(4): 507-528.

Billari, F.C. and H.-P. Kohler. 2004. "Patterns of low and lowest-low fertility in Europe." Population Studies 58(2): 161-176.

Blossfeld, H.-P. 2009. "Educational assortative marriage in comparative perspective." Annual Review of Sociology 35: 513-530.

Blossfeld, H.-P. and S. Drobnič, eds. 2001. Careers of Couples in Contemporary Society. From Male Breadwinner to Dual-Earner Families. Oxford: Oxford University Press.

Blossfeld, H.-P. and A. Timm. 2003. Who Marries Whom? Educational Systems as Marriage Markets in Modern Societies. Dordrecht: Kluwer Academic Publishers.

Bradley, Karen. 2000. "The incorporation of women into higher education: paradoxical outcomes?" Sociology of Education 73(1): 1-18.

Brown, C. and M. Corcoran. 1997. "Sex-based differences in school content and the Male-Female Wage Gap.” Journal of Labor Economics 15(3): 431-465. 
Buchmann, C. and T. A. DiPrete. 2006. "The growing female advantage in college completion: the role of family background and academic achievement." American Sociological Review 71(4): 515-541.

Buchmann, C., T.A. DiPrete and A. McDaniel. 2008. "Gender inequalities in education." Annual Review of Sociology 34: 319-337.

Çelikaksoy, A., H. Nielsen and M. Verner. 2006. "Marriage migration: just another case of positive assortative mating?" Review of Economics of the Household 4(3): 253-275.

Charles, M. and K. Bradley. 2002. "Equal but separate? A cross-national study of sex segregation in higher education." American Sociological Review 67(4): 573-599.

Cohen, J.E. 2008. "Make secondary education universal." Nature 456: 572-573.

Cooke, L.P. 2004. "The gendered division of labor and family outcomes in Germany." Journal of Marriage and Family 66(5): 1246-1259.

Cooke, L.P. 2009. "Gender equity and fertility in Italy and Spain." Journal of Social Policy 38(1): 123-140.

Corijn, M., A.C. Liefbroer and J. de Jong Gierveld. 1996. "It takes two to tango, doesn't it? The influence of couple characteristics on the timing of the birth of the first child." Journal of Marriage and the Family 58(1): 117-126.

Crowder, K.D. and S.E. Tolnay. 2000. "A new marriage squeeze for black women: the role of racial intermarriage by black men." Journal of Marriage and Family 62(3): 792-807.

de Graaf, P.M. and M. Kalmijn. 2003. "Alternative routes in the remarriage market: competing-risk analyses of union formation after divorce." Social Forces 81(4): 14591496.

Dewilde, C. and W. Uunk. 2008. "Remarriage as a Way to Overcome the Financial Consequences of Divorce." European Sociological Review 24(3): 393-407.

DiPrete, T.A. and C. Buchmann. 2006. "Gender-specific trends in the value of education and the emerging gender gap in college completion." Demography 43(1): 1-24.

Dykstra, P. and A.-R. Poortman. 2010. "Economic resources and remaining single: trends over time." European Sociological Review 26(3): 277-290.

Esteve, A., J. Garcia and I. Permanyer. 2011. "The reversal of the gender gap in eduation and its impact on union formation: the end of hypergamy." Paper presented at the Annual Meeting of the Population Association of America 2011.

European Commission. 2009. Women in Science. Luxembourg: Office for Official Publications of the European Communities.

European Commission. 2010. Report on Equality Between Women and Men. Luxembourg: European Union.

Gibson-Davis, C.M. 2009. "Money, marriage, and children: testing the financial expectations and family formation theory." Journal of Marriage and Family 71(1): 146-160.

Goldman, N. and M. Montgomery. 1989. "Fecundability and husband's age." Social Biology 36(3-4): 146-166.

Goldstein, J.R. and C.T. Kenney. 2001. "Marriage delayed or marriage forgone? New cohort forecasts of first marriage for U.S. women." American Sociological Review 66(4): 506-519.

Guttentag, M. and P.F. Secord. 1983. Too many women? The sex ratio question. Beverly Hills, CA: Sage.

Harknett, K. 2008. "Mate availability and unmarried parent relationships." Demography 45(3): 555-571. 
Härkönen, J. and J. Dronkers. 2006. "Stability and change in the educational gradient of divorce. A comparison of seventeen countries." European Sociological Review 22(5): 501-517.

Howarth, J. 1994. "Chapter 13. Women.” In The History of the University of Oxford: The Twentieth Century, ed. B. Harrison, 345-376. Oxford: Oxford University Press.

Huber, S. and M. Fieder. 2011. "Educational homogamy lowers the odds of reproductive failure." $P \operatorname{LoS} 6(7): 1-6$.

Huijts, T., C.W. Monden and G. Kraaykamp. 2010. "Education, educational heterogamy, and self-assessed health in Europe." European Sociological Review 26(3): 261-276.

Isen, A. and B. Stevenson. 2010. "Women's Education and Family Behavior: Trends in Marriage, Divorce and Fertility." In Demography and the Economy, ed. J.B. Shoven. Chicago: University of Chicago Press.

Jalovaara, M. 2012. "Socio-economic resources and first-union formation in Finland, cohorts born 1969-81." Population Studies 66(1): 69-85.

Jurajda, S. 2003. "Gender wage gap and segregation in enterprises and the public sector in late transition countries." Journal of Comparative Economics 31(2): 199-222.

Kalmijn, M. 1991(a). "Shifting Boundaries: Trends in Religious and Educational Homogamy." American Sociological Review 56(6): 786-800.

Kalmijn, M. 1991(b). "Status Homogamy in the United States." American Journal of Sociology 97(2): 496-523.

Kalmijn, M. 1993. "Spouse selection among the children of European immigrants: a comparison of marriage cohorts in the 1960 census." International Migration Review 27(1): 51-78.

Kalmijn, M. 1998. "Intermarriage and homogamy." Annual Review of Sociology 24: 395421.

Kalmijn, M. 2007. "Explaining cross-national differences in marriage, cohabitation, and divorce in Europe, 1990-2000.” Population Studies 61(3): 243-263.

KC, S., B. Barakat, A. Goujon, V. Skirbekk, W. Sanderson and W. Lutz. 2010. "Projection of populations by level of educational attainment, age, and sex for 120 countries for 2005-2050." Demographic Research 22(15): 383-472.

Kofman, E. 2004. "Family-related migration: a critical review of European studies." Journal of Ethnic and Migration Studies 30(2): 243-262.

Köppen, K. 2006. "Second births in western Germany and France." Demographic Research 14(14): 295-330.

Kravdal, Ø. 1999. "Does marriage require a stronger economic underpinning than informal cohabitation." Population Studies 53(1): 63-80.

Kravdal, Ø. and R.R. Rindfuss. 2008. "Changing relationships between education and fertility a study of women and men born 1940-64." American Sociological Review 73(5): 854-873.

Lichter, D.T., F.B. LeClere and D.K. McLaughlin. 1992. "Local marriage markets and the marital behavior of black and white women." American Journal of Sociology 96(4): 843-867.

Lievens, J. 1999. "Family-forming migration from Turkey and Morocco to Belgium: the demand for marriage partners from the countries of origin." International Migration Review 33(3): 717-744.

Lutz, W., A. Goujon and G. Doblhammer-Reiter. 1998. "Demographic dimensions in forecasting: adding education to age and sex." Population and Development Review 24(Supplement): 42-58. 
Lutz, W., A. Goujon, S. K.C. and W. Sanderson. 2007. „Reconstruction of population by age, sex and level of educational attainment of 120 countries for 1970-2000." Vienna Yearbook of Population Research 2007(5): 193-235.

Lutz, W., J.C. Cuaresma and W. Sanderson. 2008. "The demography of educational attainment and economic growth." Science 319(5866): 1047-1048.

McDaniel, A. 2010. The Gender Gap in Higher Education in Europe: the Impact of Individual and National Characteristics. Ohio State Univ., unpubl. working paper.

McDonald, P. 2000. "Gender equity in theories of fertility transition." Population and Development Review 26(3): 427-439.

Machin, S. and P.A. Puhani. 2003. "Subject of degree and the gender wage differential: evidence from the UK and Germany." Economics Letters 79(3): 393-400.

McLanahan, S. 2004. "Diverging destinies: how children are faring under the second demographic transition." Demography 41(4): 607-627.

Mandel, H. and M. Semyonov. 2006. "A welfare state paradox: state interventions and women's employment opportunities in 22 countries." American Journal of Sociology 111(6): 1910-1949.

Mare, R.D. 1991. "Five decades of educational assortative mating." American Sociological Review 56(1): 15-32.

Mascie-Taylor, C.G.N. 1986. "Assortative mating and differential fertility." Biology and Society 3(4): 167-70.

Matorras, R., F. Matorras, A. Expósito, L. Martinez and L. Crisol. 2011. "Decline in human fertility rates with male age: a consequence of a decrease in male fecundity with aging?" Gynecologic and Obstetric Investigation 71(4): 229-235.

Myrskylä, M., H.-P. Kohler, and F.C. Billari. 2009. "Advances in development reverse fertility declines.” Nature 460(6 August): 741-743.

Myrskylä, M., H.-P. Kohler and F.C. Billari. 2011. High Development and Fertility: Fertility at Older Reproductive Ages and Gender Equality Explain the Positive Link. Rostock, Germany: Max Planck Institute for Demographic Research. (MPIDR Working Paper WP 2011-017.)

Oppenheimer, V.K. 1988. "A theory of marriage timing." American Journal of Sociology 94(3): 563-591.

Rindfuss, R.R. and A. VandenHeuvel. 1990 . "Cohabitation: a precursor to marriage or an alternative to being single." Population and Development Review 16(4): 703-726.

Rose, E. 2004. Education and Hypergamy in Marriage Markets. Washington, WA: Center for Research on Families, University of Washington. (Center for Research on Families Working Paper 2004-01.)

Rosina, A. and M.R. Testa. 2009. "Couples' first child intentions and disagreement: an analysis of the Italian case.” European Journal of Population 25(4): 487-502.

Schoen, R. 1983. "Measuring the tightness of the marriage squeeze." Demography 20(1): 61-78.

Schofer, E. and J.W. Meyer. 2005. "The worldwide expansion of higher education in the twentieth century." American Sociological Review 70(6): 898-920.

Schwartz, C.R. and R.D. Mare. 2005. "Trends in educational assortative marriage from 1940 to 2003." Demography 42(4): 621-646.

Shafer, K.M. 2009. "Gender Differences in Remarriage: Marriage Formation and Assortative Mating After Divorce.” PhD diss., Ohio State Univ., Columbus, Ohio.

Sobotka, T. 2004. "Is lowest-low fertility in Europe explained by the postponement of childbearing?” Population and Development Review 30(2): 195-220. 
Sobotka, T and L. Toulemon. 2008. "Overview Chapter 4: Changing family and partnership behaviour: Common trends and persistent diversity across Europe." Demographic Research 19(6): 85-138.

Soons, J.P.M., A.C. Liefbroer and M. Kalmijn. 2009. "The long-term consequences of relationship formation for subjective well-being." Journal of Marriage and Family 71(5): 1254-1270.

South, S.J., K. Trent and Y. Shen. 2001. "Changing partners: towards a macrostructuralopportunity theory of marital dissolution." Journal of Marriage and the Family 63(3): 743-754.

Sweeney, M.M. and M. Cancian. 2004. "The changing importance of white woman's economic prospects for assortative mating." Journal of Marriage and Family 66(4): 1015-1028.

Teachman, J.D. 2002. "Stability across cohorts in divorce risk factors" Demography 39(2): 331-351.

Thomson, E. 1990. "Two in one: structural models of couple behaviour." In Family Variables: Conceptualization, Measurement and Use, ed. C.W. Draper and A.C. Marcos, 129-142. Newbury Park, CA: Sage.

Thomson, E., E. McDonald, and L. Bumpass. 1990. "Fertility desires and fertility." Demography 27(4): 579-588.

Thomson, E. 2001. "Family size preferences." In International Encyclopedia of the Social \& Behavioral Sciences, 5347-5350. Amsterdam: Elsevier.

Timmerman, C. 2008. "Marriage in a 'culture of migration'. Emirdag marrying into Flanders." European Review 16(4): 585-594.

Torr, B.M. and S.E. Short. 2004. "Second births and the second shift: a research note on gender equity and fertility." Population and Development Review 30(1): 109-130.

Van Bavel, J. 2010. Choice of study discipline and the postponement of motherhood in Europe: the impact of expected earnings, gender composition and family attitudes, Demography 47(2): 439-458.

Van Bavel, J. and J. Różańska-Putek. 2010. "Second birth rates across Europe: childcare as a mediator of the effect of women's level of education." Vienna Yearbook of Population Research 2010(8): 107-138.

Van Bavel, J., M. Jansen and B. Wijckmans. 2012. "Has divorce become a pro-natal force in Europe at the turn of the 21st century?" Population Research and Policy Review.

Van de Putte, B., F. van Poppel, S. Vanassche et al.. 2009. "The rise of age homogamy in 19th century Western Europe.” Journal of Marriage and Family 71(5): 1234-1253.

Vincent-Lancrin, S. 2008. "The Reversal of Gender Inequalities in Higher Education: an Ongoing Trend." In Higher Education to 2030: Demography, 265-98. Paris: OECD.

Voas, D. 2004. "Conflicting preferences: a reason fertility tends to be too high or too low" Population and Development Review 29(4): 627-646.

West, C. and D. Zimmerman. 1987. "Doing gender." Gender and Society 1(2): 125-151.

Wilson, K.L. and J.P. Boldizar. 1990. "Gender segregation in higher education: effects of aspirations, mathematics achievement, and income." Sociology of Education 63(1): 62-74. 